\title{
The Relationship between Bone Density at Implant Sites and Primary Implant Stability
}

\author{
Zhang Yingying, Zhang Zhihong*, Liu Honghong, Lv Jing, Han Qian, Chen Jia, Tian Tian and Li Mengqi \\ Department of Stomatology, The First Affiliated Hospital of University of Science and Technology of China (Anhui Provincial hospital), Hefei, China
}

*Corresponding author: Zhang Zhihong, Department of Stomatology, The First Affiliated Hospital of University of Science and Technology of China (Anhui Provincial hospital), 17 Lujiang Road, Luyang District, Hefei, China, E-mail: zzhzqr@126.com

Received: 03 Jun, 2021 | Accepted: 14 Jun, 2021 | Published: 24 Jun, 2021

Citation: Yingying Z, Zhihong Z, Honghong L, Jing L, Qian H, et al. (2021) The Relationship between Bone Density at Implant Sites and Primary Implant Stability. Int J Dent Oral Health 7(5): dx.doi.org/10.16966/2378-7090.370

Copyright: (C) 2021 Yingying Z, et al. This is an open-access article distributed under the terms of the Creative Commons Attribution License, which permits unrestricted use, distribution, and reproduction in any medium, provided the original author and source are credited.

\begin{abstract}
Objective: The aim of this study was to analyse the relationship between bone density derived from cone-beam computerized tomography (CBCT) scanning combined with the Simplant software at the implant site and primary implant stability.

Materials and methods: A total of 88 implants were placed on75 patients (41 males and 34 females) who underwent dental implant surgery at the Stomatology Center of the First Affiliated Hospital of University of Science and Technology of China (Anhui Provincial Hospital) were chosen from June 2018 to December 2019, with an average age of (42.20 \pm 15.34$)$ years old. The bone densities at implant sites were preoperatively calculated applying CBCT scanning and Simplant software in Hounsfield Unit (HU). The peak insertion torque was recorded, and the resonance frequency analysis (RFA) was used to measure the implant stability quotient (ISQ) during the implant placement. Statistical analysis was taken to assess the association between bone density and primary implant stability.

Results: The bone density values ranged from $341.27 \mathrm{HU}$ to $826.63 \mathrm{HU}$. It was shown that the mean bone density, insertion torque and ISQ values were $(609.38 \pm 133.62) \mathrm{HU},(36.61 \pm 9.59) \mathrm{N} . \mathrm{cm}, 58.87 \pm 11.48$, respectively. There were statistically significant correlations between insertion torque and ISQ values $(r=0.811, p=0.000)$, bone density and insertion torque $(r=0.872, p=0.000)$, and bone density and ISQ values ( $r=0.857, p=0.000)$.

Conclusion: There may be a strong positive correlation between bone density and primary implant stability. Sufficient preoperative evaluation of the bone density of implant sites can provide a reference for predicting the primary implant stability.
\end{abstract}

Keywords: Bone density; Implant stability; Insertion torque; Resonance frequency analysis

\section{Introduction}

Dental implants have gradually become an effective method for patients who are partially or completely edentulous [1,2]. Osseointegration is related to the bone-to-implant contact ratio and bone quality usually considered being a prerequisite for implant loading and long-term success rate during dental implant surgery. However, the assessment of osseointegration by histomorphometric analysis is not accessible to clinicians all the time. Compared with the histological methods, assessment of the implant stability appears to be particularly convenient.

The primary implant stability that is evaluated by insertion torque and resonance frequency analysis is regarded as one of the most important factors that can affect osseointegration [3]. The insertion torque is mainly referred to as a power that resists the implant be pulled out from the implant site, which indicates the local bone quality. It is clear that primary stability can be influenced by the operation ways, implant shape, surface treatment methods of implant, and the quantity and quality of remaining bone in edentulous alveolar ridge [4-6].
Bone density, an objective indicator to evaluate bone quality has been researched by many scholars [7-9]. Bone density is generally measured with dual X-ray absorptiometry and computerized tomography. Three-dimensional CBCT rather than the multi-slice spiral computerized tomography (MSCT) is used to measure the bone density at implant sites in this study, regarding the superiority of high solution and low radiation dose. However, because of the uncertain gray values and multiform artifacts of CBCT, it is not exactly to directly measure the bone density at implant sites with CBCT. Preoperative planning software called Simplant is used to measure bone density more accurately. Furthermore, implant sites of poorer qualities demonstrated higher failure rates than better bone quality [10]. Therefore, it is particularly critical to evaluate the bone density of dental implant sites before implant placement. Alveolar bone density can be used to predict bone strength and bone quality, which is one of the factors that affect primary implant stability [11]. At present, the assessment of bone density at implant sites relies on preoperative imaging data or intraoperatively empirical judgment of the surgeon $[7,12]$. This study provides an objective method to measure bone density at implant sites. 
The first aim of this study is to measure the bone density at implant sites using Simplant software combined with CBCT scanning before implant placement. The second aim is to record the peak insertion torque and ISQ values during the dental implant surgery and analyse the relationship between bone density and primary implant stability.

\section{Materials and Methods}

\section{Experiment Patients}

Seventy-five patients (41 males and 34 females) who underwent dental implant surgery at Stomatology Center of the First Affiliated Hospital of USTC (Anhui Provincial Hospital) were chosen from June 2018 to December 2019, with an average age of $(42.20 \pm 15.34)$ years old. A total of 88 implants were used and of which 48 were males, the other 40 were for females. This research has been approved by the local ethical committee of Anhui Provincial Hospital (Ethics No: 2018-ky019). Written informed consent was obtained from patients participating in this study.

\section{Study design}

All enrolled patients were asked if they would like to participate in the study, and patients met the inclusion criteria. The content on the informed consent by an explanation, the researchers let patients after fully understand and agree to sign it.

\section{Inclusion and exclusion criteria}

\section{Inclusion criteria:}

- $\mathrm{CBCT}$ scans that showed the alveolar bone in recipient cites were intact without deformity;

- CBCT scans that showed the effective residual bone volumes of at least $10 \mathrm{~mm}$ in height;

- Dental extractions for at least 3 months;

- Patients aged over 18 years, well-informed and willing to sign informed consent for surgery.

\section{Exclusion criteria:}

- Patients who have uncontrollable systemic diseases that are contraindicated in dental implant surgery;

- A history of long-term use of non-steroidal drugs;

- A history of intravenous or oral bisphosphonates treatment;

- Currently suffering from untreated periodontitis;

- Patients with poor oral hygiene and compliance.

\section{CBCT scanning conditions}

A CBCT machine (SS-X9010DPro-3D, Hefei Meiya Optoelectronic Technology Co., Ltd., Hefei, China) was used to obtain preoperative imaging of experiment patients, which worked in conditions as follows: a tube voltage of $90 \mathrm{kV}$, a tube current of $10 \mathrm{~mA}$, a scan time of 20 seconds, a scanning layer thickness of $0.13 \mathrm{~mm}$, and a reconstruction layer thickness of $0.25 \mathrm{~mm}$. Finally, the scanned data was saved in Digital Imaging and Communications in Medicine (DICOM) format.

\section{Bone mineral density measurement at implant sites}

CBCT scanning of the patients was entering into SIMPLANT 17.0 (DENTSPLY Implants, Leuven, Belgium) in Dicom format. This work chosen a reference plane based on the neck of adjacent teeth of the edentulous area and selected the coronal image of the center point of the implant site (Figure 1A). Subsequently, a panoramic line was drawn along the direction of the arch (Figure 1B) and then an implant simulation at the implant site was performed (Figure 1C), avoiding important anatomical structures. Dental implants with diameter 3.3 $\mathrm{mm}, 4.1 \mathrm{~mm}$ and length $10 \mathrm{~mm}$ Straumann ${ }^{\circ}$ soft-tissue level system were used in this study. With the function of bone density calculation in the Simplant software, bone density expressed in HU within $1 \mathrm{~mm}$ around the implant was measured (Figure 1D).

\section{Insertion torque and ISQ value measurements}

The standard surgical guides of Straumann ${ }^{\circledR}$ soft-tissue level implants (Straumann Holding AG, Basel, Switzerland) were used for dental implant placement. All the enlarged neck structures of the implants do not enter the bone tissue. Insertion torque range from $0-50$ N.cm on the KaVo implanter (KaVo, Biberach, Germany) gradually increased during the implant placement. When the implant stopped rotating and reached the final position, the peak insertion torque during the placement was recorded. Based on the way of resonance frequency analysis, Osstell ${ }^{\text {is }}$ mentor (Osstell AB, Göteborg, Sweden) with a Smartpeg $^{\text {mi }}$ (Osstell AB, Göteborg, Sweden) attached to implant by 5 N.cm was used to record ISQ values (Figure 2). The measurements were accompanied by buccolingual and mesiodistal directions. The same doctor took the second measurement in each direction and used the average value.

\section{Statistical analysis}

All the data were statistically calculated by SPSS17.0 software (SPSS Inc. Chicago, America). Values are represented by means \pm standard deviation. The single-sample Kolmogorov-Smirnov test verifies whether the variable satisfies the normal distribution. The Pearson correlation coefficient was used to test the relationship between bone density and primary implant stability. The independent-sample t-test and Mann-Whitney $U$ test were used to compare the differences in bone density, insertion torque and ISQ values in different genders, implant diameters, maxillary and mandibular, and anterior and posterior implant sites. $\mathrm{P}<0.05$ was considered statistically significant.

\section{Results}

The mean measurements of bone density, insertion torque and ISQ values were $(609.38 \pm 133.62) \mathrm{HU},(36.61 \pm 9.59) \mathrm{N} . \mathrm{cm}$, and $58.87 \pm$ 11.48, respectively. According to the Kolmogorov-Smirnov test, all meet the normal distribution and the Pearson correlation coefficient was used. The correlation between insertion torque and ISQ values was found to be statistically significant $(\mathrm{r}=0.811, \mathrm{p}<0.05)$ (Figure $3 \mathrm{~A}$ ), while the difference in correlation between bone density and insertion torque and ISQ values was statistically significant too $(\mathrm{r}=0.872$ and $\mathrm{r}=0.857$, respectively, $\mathrm{p}<0.05$ ) (Figure $3 \mathrm{~B}$ and $3 \mathrm{C}$ ).

The average bone density was $(609.38 \pm 133.62) \mathrm{HU}$ with a range from $341.27 \mathrm{HU}$ to $826.63 \mathrm{HU}$. There were 23 anterior maxillary sites, 21 posterior maxillary sites, 20 anterior mandibular sites, and 24 posterior mandibular sites. The mean bone density was $(623.65 \pm$ 31.36) HU, (424.90 \pm 68.19$) \mathrm{HU},(786.51 \pm 28.51) \mathrm{HU}$ and $(609.53 \pm$ 57.61) HU, respectively. Except for no significant differences in bone density at implant sites between anterior maxillary and posterior mandibular $(\mathrm{t}=1.038, \mathrm{p}=0.305)$, there were statistically significant differences between each other $(\mathrm{p}<0.001)$. The range of bone density at different implant sites as shown below (Figure 4), displayed that bone density of anterior mandibular sites $>$ anterior maxillary sites $>$ posterior mandibular sites $>$ posterior maxillary sites sorted by size.

The independent-sample t-test and Mann-Whitney $U$ test were used to compare the differences in bone density, insertion torque and ISQ values in different groups. Measurement results and statistical values were shown below (w 1). There was no statistically significant 

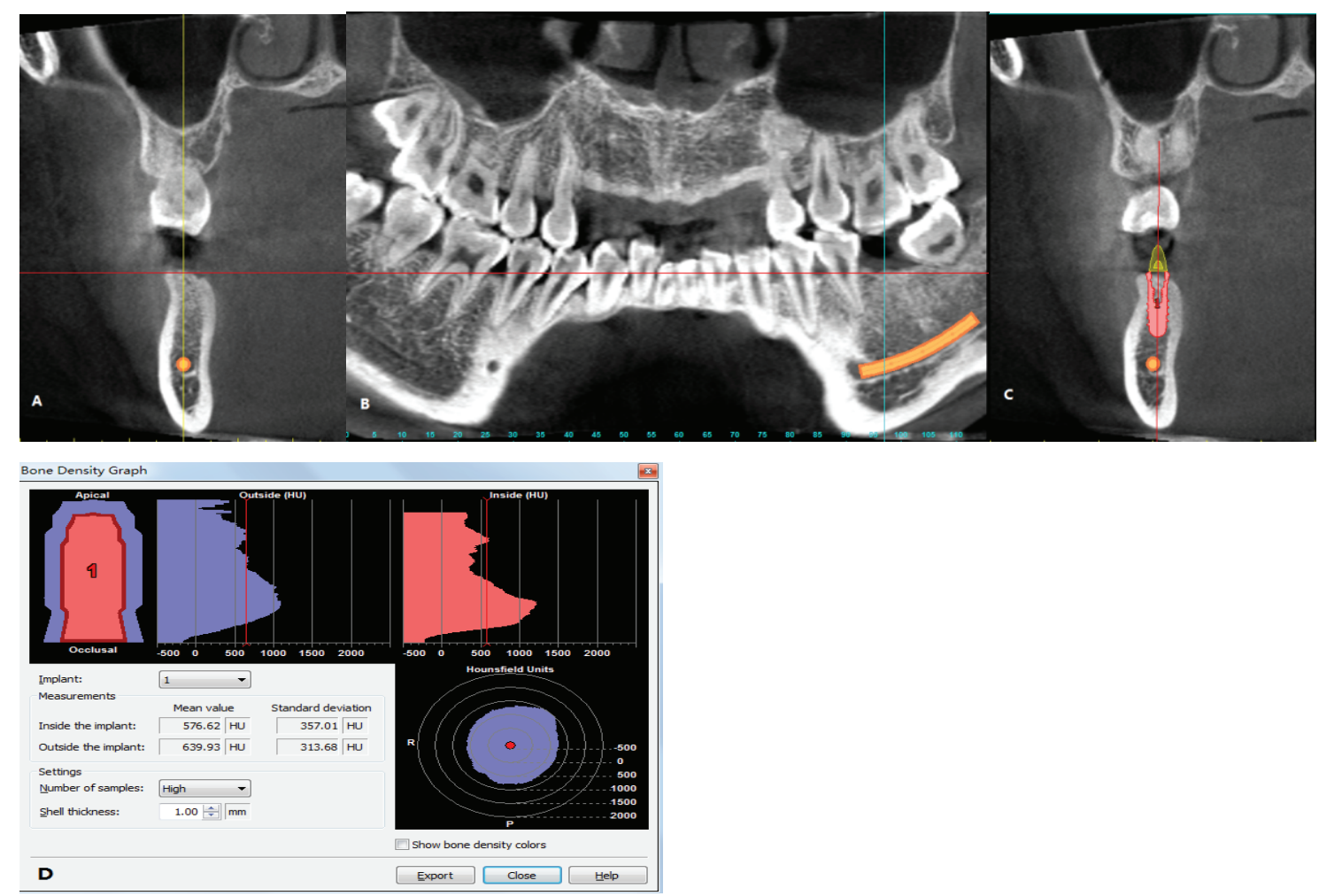

Figure 1: Bone density measurement at implant site.

A: Coronal image of the center point of the implant site.

B: Panoramic image of the patient.

C: Simulate implant placement.

D: Calculate the bone density.

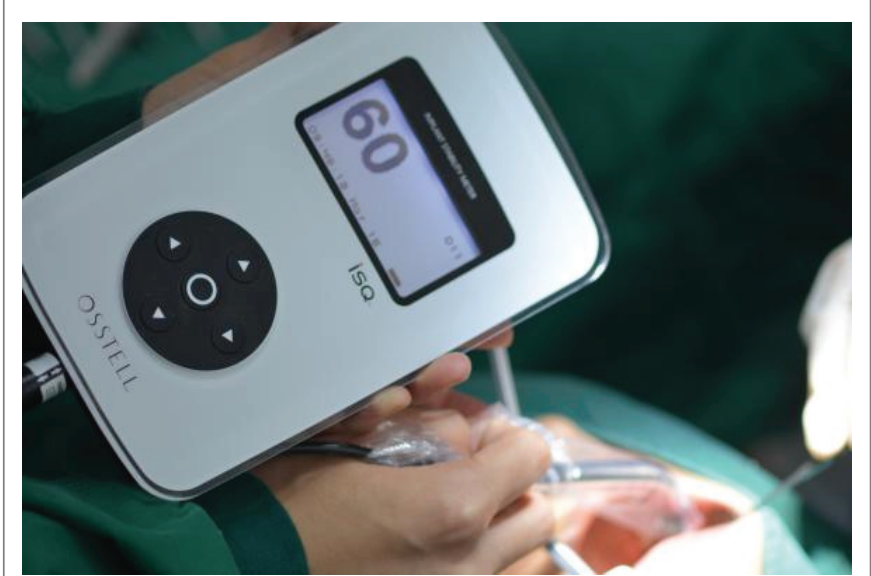

Figure 2: Measurement of implant stability quotient values.

difference between different genders ( $p>0.05$ ). There were statistically significant in three variables measurements between maxillary and mandibular $(\mathrm{p}<0.05)$, anterior and posterior implant sites $(\mathrm{p}<0.05)$, the diameter of $3.3 \mathrm{~mm}$ and $4.1 \mathrm{~mm}(\mathrm{p}<0.05)$. Bone density and primary implant stability demonstrated more superior in mandibular than maxillary during the placement.

\section{Discussion}

Today, dental implant technology has been widely used to restore the function and aesthetics of edentulous patients. Osseointegration and long-term success rate after implant placement depended on favourable primary implant stability and sufficient bone of the implant sites. The bone density of the recipient sites directly affects primary implant stability $[13,14]$. The preoperative assessment of the bone density of recipient sites helped clinicians to make an appropriate implant treatment plan and improve the success rate of placement. However, accurate imageological examination was required for preoperative evaluation of the bone density of the jaws. The gray value derived from $\mathrm{CBCT}$ scanning has been demonstrated a strong positive correlation with the density of known objects, but it is not yet clear about the accuracy of using gray values to directly represent the bone density of implant sites [15].

At present, the measurement of bone density based on СBCT scanning is mainly utilized for the assessment of the bone quality of the implant sites [16]. Due to many artifacts and scattering shadows generated in a CBCT scanning, this has an effect on the assessment of bone density at implant sites [17]. The CBCT image was managed with Simplant software to objectively measure the bone density at implant sites in this study. Some scholars have researched bone density at different regions of jaws. Turkyilmaz I, et al., [18] measured the bone density of 131 implant sites, the results showed that the average bone 
Table 1: Measurement results of different groups and statistical value.

\begin{tabular}{|c|c|c|c|c|}
\hline \multicolumn{2}{|c|}{ Variables } & Insertion torque (N.cm) & ISQ & Bone density (HU) \\
\hline \multirow{4}{*}{ Gender } & Male $(n=48)$ & $36.15 \pm 10.27$ & $58.18 \pm 12.03$ & $600.24 \pm 141.28$ \\
\hline & Female $(n=40)$ & $37.10 \pm 8.70$ & $59.70 \pm 10.87$ & $620.36 \pm 124.69$ \\
\hline & Test & t test & t test & $\mathrm{t}$ test \\
\hline & $p$ & 0.643 & 0.54 & 0.485 \\
\hline \multirow{4}{*}{ Area } & Maxillary ( $n=44)$ & $32.34 \pm 8.62$ & $53.32 \pm 10.48$ & $528.79 \pm 112.92$ \\
\hline & Mandibular $(n=44)$ & $40.82 \pm 8.57$ & $64.43 \pm 9.67$ & $689.98 \pm 100.41$ \\
\hline & Test & Mann-Whitney U test & $\mathrm{t}$ test & t test \\
\hline & $p$ & 0 & 0 & 0 \\
\hline \multirow{4}{*}{ Area } & Anterior $(n=43)$ & $42.02 \pm 5.36$ & $65.28 \pm 8.70$ & $699.40 \pm 87.40$ \\
\hline & Posterior $(n=45)$ & $31.38 \pm 9.81$ & $52.75 \pm 10.47$ & $523.37 \pm 111.91$ \\
\hline & Test & $\mathrm{t}$ test & t test & t test \\
\hline & $\mathrm{p}$ & 0 & 0 & 0 \\
\hline \multirow{4}{*}{ Diameter (mm) } & $3.3(n=52)$ & $42.02 \pm 5.36$ & $65.28 \pm 8.70$ & $699.40 \pm 87.40$ \\
\hline & $4.1(n=36)$ & $31.38 \pm 9.81$ & $52.75 \pm 10.47$ & $523.37 \pm 111.91$ \\
\hline & Test & t test & t test & t test \\
\hline & $p$ & 0 & 0 & 0 \\
\hline
\end{tabular}
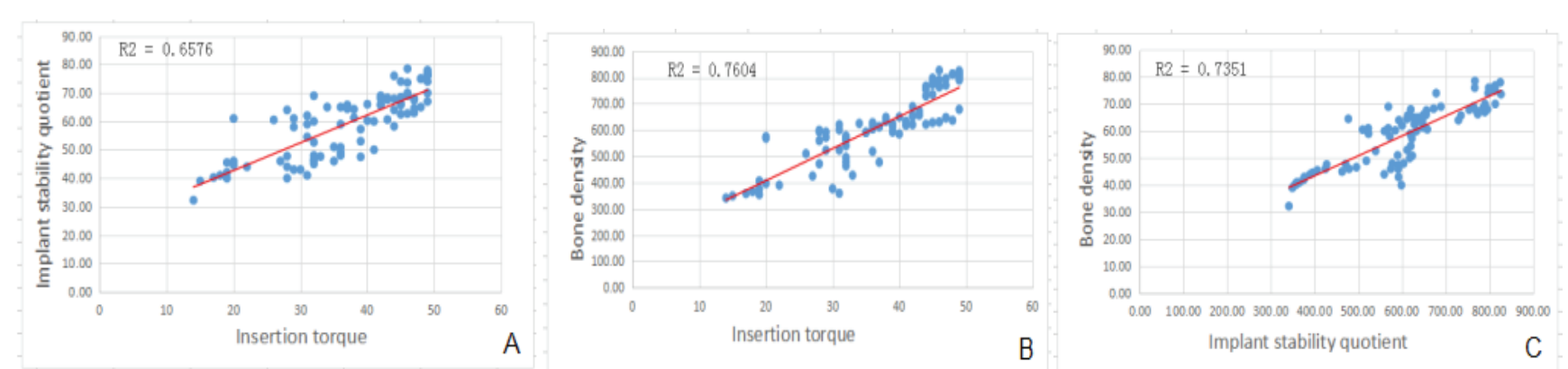

Figure 3: Scatter plots between insertion torque, implant stability quotient values and bone density.

A: Scatter plot of insertion torque and implant stability quotient values.

B: Scatter plot of insertion torque and bone density.

C: Scatter plot of implant stability quotient values and bone density.

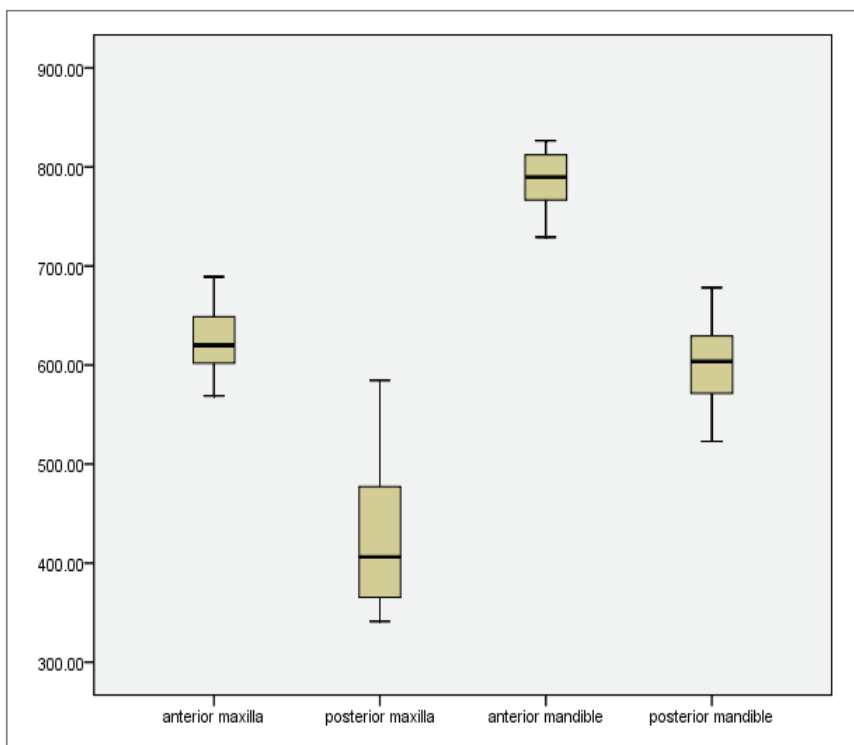

Figure 4: Bone density range in different regions of the jaws. density of the anterior mandible, the anterior maxillary, the posterior mandibular, and the posterior maxillary was $944.9 \mathrm{HU}, 715.8 \mathrm{HU}, 674.3$ $\mathrm{HU}$ and $455.1 \mathrm{HU}$, respectively. The results of their study were higher than that in this work, probably due to the equipment used to obtain patients' radiological information was discrepant. The measurement of bone density at recipient sites by spiral CT was relatively higher than that by CBCT. Another study that based on CBCT images combined with Simplant software was aimed to analyze the alveolar bone density of dentulous and edentulous region in the Saudi population [19]. In terms of edentulous regions, the bone density of the anterior mandibular implant sites was $(776.5 \pm 65.7 \mathrm{HU})$, the bone density of the posterior Mandibular implant sites was $(502.2 \pm 224.2 \mathrm{HU})$, the bone density of the posterior maxillary and the anterior maxillary was $(320.05 \pm 193.6 \mathrm{HU})$ and $(313.84 \pm 190.7 \mathrm{HU})$, respectively. The bone density in edentulous region is lower than the bone density in this study, which may be related to the race and age of the experiment patients.

Primary implant stability played a key role in evaluating the success of dental implant surgery. It mainly maintained a low micromovement during the early healing time of the dental implant and promoted the combination of bone and the surface of the implant 
[20,21]. Therefore, the acquirement of primary implant stability during the implant placement was crucially important. There was a strong positive correlation between bone density and primary implant stability. We found higher primary implant stability at implant sites with greater bone density, such as mandibular vs. Maxillary and posterior $v s$. anterior. This means that the higher the bone density, the better the initial stability of the implant.

Many scholars had explored the relationship between the bone density of the jaws and the primary implant stability, but the controversy was always remained. Insertion torque and ISQ presented higher in anterior regions than posterior regions both in maxillary and mandibular, which was similar to the foundation of Turkyilmaz I, et al., [22]. Turkyilmaz I, et al., used three mandibular human cadavers to explore the correlation between bone density and primary implant stability. They found that the bone density and primary implant stability between the anterior and posterior implant sites shown a statistically significant difference $(\mathrm{p}<0.05)$. A study by Isoda $\mathrm{K}$, et al., [23] placed 18 Straumann system dental implants into 18 fresh pig femorals with CBCT. The results showed that the correlation coefficient between insertion torque and ISQ values was 0.758 . The correlation coefficients between bone density and insertion torque and ISQ values were 0.796 and 0.529 , respectively, which had statistically significant differences ( $\mathrm{p}<0.05)$. Joe $\mathrm{M}$, et al., placed 195 dental implants into 48 edentulous patients with a digital guide plate. The results indicated that bone density has an important influence on implant stability. The ISQ value of the cancellous bone has the highest correlation with bone density $(r=0.64)$. Slight differences in correlation coefficients may be due to different implant brands used, different study subjects, and different surgical procedures. However, it has been demonstrated that no correlation between insertion torque and ISQ values by Friberg B, et al., [24] and da Cunha HA, et al., [25]. Many clinical studies [26-30] indicated that different types of alveolar bone have a certain effect on primary implant stability. The bone density at implant sites not only includes the trabecular bone but the cortical bone, only the trabecular bone structure around the implant was involved. This may be a limitation of this study and further research would be performed to increase the reliability. Due to the limited sample size in this study, there was no classification of the jaws and no discussion about the influence of the quality of jaws on the primary implant stability. In future studies, the sample size would be enlarged to research the relationship between alveolar bone classification and primary implant stability, so as to enhance the persuasiveness of the data in this study.

\section{Conclusion}

Simplant software combined with CBCT scanning can be used to objectively assess the alveolar bone density. Insertion torque and RFA method are effective ways to the intraoperative evaluation of the primary implant stability. A full preoperative assessment of the alveolar bone density has access to predict primary implant stability.

\section{Acknowledgment}

This work was supported by the Special Project of Science and Technology Development of Central Leading Local in Anhui Province, 2018 (YDZ-X20183400004841). The authors declare no potential conflicts of interest with respect to the authorship of this article.

\section{References}

1. Alghamdi HS, Jansen JA (2020) The development and future of dental implants. Dent Mater J 39: 167-172.
2. Hatzimanolakis P, Tsourounakis I, Kelekis-Cholakis A (2019) Dental Implant Maintenance for the Oral Healthcare Team. Compend Contin Educ Dent 40: 424-430.

3. Malchiodi L, Balzani L, Cucchi A, Ghensi P, Nocini PF (2016) Primary and secondary stability of implants in postextraction and healed sites: a randomized controlled clinical trial. Int J Oral Maxillofac Implants 31: 1435-1443.

4. Lozano-Carrascal N, Salomó-Coll O, Gilabert-Cerdà M, Farré-Pagés N, Gargallo-Albiol J, et al. (2016) Effect of implant macro-design on primary stability: A prospective clinical study. Med Oral Patol Oral Cir Bucal 21: e214-e221.

5. Merheb J, Temmerman A, Rasmusson L, Kübler A, Thor A, et al. (2016) Influence of Skeletal and Local Bone Density on Dental Implant Stability in Patients with Osteoporosis. Clin Implant Dent Relat Res 18: 253-260.

6. Kim NH, Lee SH, Ryu JJ, Choi KH, Huh JB (2015) Effects of rhBMP-2 on Sandblasted and Acid Etched Titanium Implant Surfaces on Bone Regeneration and Osseointegration: Spilt-Mouth Designed Pilot Study. Biomed Res Int 459393.

7. Parsa A, Ibrahim N, Hassan B, van der Stelt P, Wismeijer D (2015) Bone quality evaluation at dental implant site using multislice $\mathrm{CT}$, micro-CT, and cone beam CT. Clin Oral Implants Res 26: e1-e7.

8. Varshowsaz M, Goorang S, Ehsani S, Azizi Z, Rahimian S (2016) Comparison of Tissue Density in Hounsfield Units in Computed Tomography and Cone Beam Computed Tomography. J Dent (Tehran) 13: 108-115.

9. Di Stefano DA, Arosio P, Pagnutti S, Vinci R, Gherlone EF (2019) Distribution of Trabecular Bone Density in the Maxilla and Mandible. Implant Dent 28: 340-348.

10. Chrcanovic BR, Albrektsson T, Wennerberg A (2017) Bone Quality and Quantity and Dental Implant Failure: A Systematic Review and Meta-analysis. Int J Prosthodont 30: 219-237.

11. Muller R (2003) Bone microarchitecture assessment: current and future trends. Osteoporos Int 14: 89-99.

12. Lee S, Gantes B, Riggs M, Crigger M (2007) Bone density assessments of dental implant sites: 3 . Bone quality evaluation during osteotomy and implant placement. Int J Oral Maxillofac Implants 22: 208-212.

13. Turkyilmaz I, McGlumphy EA (2008) Influence of bone density on implant stability parameters and implant success: a retrospective clinical study. BMC Oral Health 8: 32.

14. Bergkvist G, Koh KJ, Sahlholm S, Klintström E, Lindh C (2010) Bone density at implant sites and its relationship to assessment of bone quality and treatment outcome. Int J Oral Maxillofac Implants 25: 321-328.

15. Reeves TE, Mah P, McDavid WD (2012) Deriving Hounsfield units using gray levels in cone beam CT: a clinical application. Dentomaxillofac Radiol 41: 500-508.

16. Benavides E, Rios HF, Ganz SD, An CH, Resnik R, et al. (2012) Use of cone beam computed tomography in implant dentistry: the International Congress of Oral Implantologists consensus report. Implant Dent 21: 78-86.

17. Schulze RK, Berndt D, d'Hoedt B (2010) On cone-beam computed tomography artifacts induced by titanium implants. Clinical Oral Implants Research 21: 100-107.

18. Turkyilmaz I, Tözüm TF, Tumer C (2007) Bone density assessments of oral implant sites using computerized tomography. J Oral Rehabil 34: 267-272. 
19. Almasoud NN, Tanneru N, Marei HF (2016) Alveolar bone density and its clinical implication in the placement of dental implants and orthodontic mini-implants. Saudi Med J 37: 684-689.

20. Voumard B, Maquer G, Heuberger P, Zysset PK, Wolfram U (2018) Peroperative Estimation of Bone Quality and Primary Dental Implant Stability. J Mech Behav Biomed Mater 92: 24-32.

21. Capparé P, Vinci R, Di Stefano DA, Traini T, Pantaleo G, et al. (2015) Correlation between Initial BIC and the Insertion Torque/Depth Integral Recorded with an Instantaneous Torque-Measuring Implant Motor: An in vivo Study. Clin Implant Dent Relat Res 17: e613-e620.

22. Turkyilmaz I, Sennerby L, McGlumphy EA, Tözüm TF (2009) Biomechanical aspects of primary implant stability: a human cadaver study. Clin Implant Dent Relat Res 11: 113-119.

23. Isoda K, Ayukawa Y, Tsukiyama Y, Sogo M, Matsushita Y, et al. (2012) Relationship between the bone density estimated by cone-beam computed tomography and the primary stability of dental implants. Clin Oral Implants Res 23: 832-836.

24. Friberg $B$, Jisander $S$, Widmark $G$, Lundgren $A$, Ivanoff $C$, et al (2003) One-year prospective three-center study comparing the outcome of a "soft bone implant" (prototype Mk IV) and the standard Brånemark implant. Clin Implant Dent Relat Res 5: 71-77.
25. da Cunha HA, Francischone CE, Filho HN, de Oliveira RC (2004) A comparison between cutting torque and resonance frequency in the assessment of primary stability and final torque capacity of standard and TiUnite single-tooth implants under immediate loading. Int J Oral Maxillofac Implants 19: 578-585.

26. Merheb J, Vercruyssen M, Coucke W, Quirynen M (2018) Relationship of implant stability and bone density derived from computerized tomography images. Clin Implant Dent Relat Res 20: 50-57.

27. Sakka S, Coulthard P (2009) Bone quality: a reality for the process of osseointegration. Implant Dent 18: 480-485.

28. Li J, Yin X, Huang L, Mouraret S, Brunski JB, et al. (2017) Relationships among Bone Quality, Implant Osseointegration, and Wnt Signaling. J Dent Res 96: 822-831.

29. Sargolzaie N, Samizade S, Arab H, Ghanbari H, Khodadadifard L, et al. (2019) The evaluation of implant stability measured by resonance frequency analysis in different bone types. J Korean Assoc Oral Maxillofac Surg 45: 29-33.

30. Ribeiro-Rotta RF, de Oliveira RC, Dias DR, Lindh C, Leles CR (2014) Bone tissue microarchitectural characteristics at dental implant sites part 2: correlation with bone classification and primary stability. Clin Oral Implants Res 25: e47-e53. 